Mrozkowiak Miroslaw. The incidence of significant correlations between body height and weight and foot parameters among 7-13year-old children of both sexes and environments. Pedagogy and Psychology of Sport. 2021;7(2):94-105. elSSN 2450-6605. DOI http://dx.doi.org/10.12775/PPS.2021.07.02.007

https://apcz.umk.pl/czasopisma/index.php/PPS/article/view/PPS.2021.07.02.007

https://zenodo.org/record/4742555

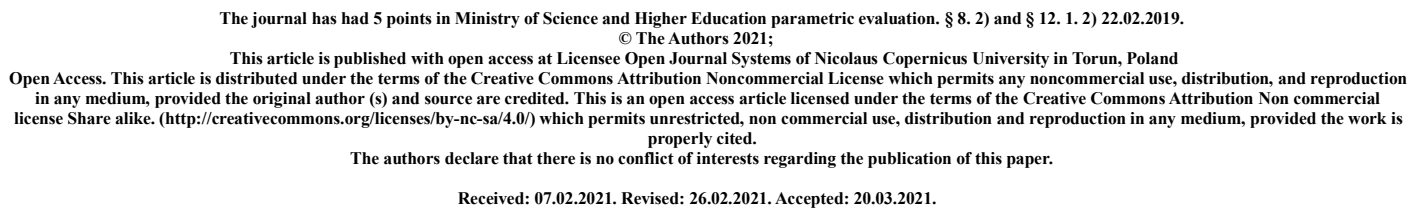

\title{
The incidence of significant correlations between body height and weight and foot parameters among 7-13-year-old children of both sexes and environments
}

Mirosław Mrozkowiak

Gabinet Akton, Poznań, Poland

\begin{abstract}
The purpose of this study was to present the incidence of significant correlations between body weight and height and the selected parameters of feet among 7-13-year-old children.

Material and methods. The study which was conducted among children aged 7-13 years during the period of 3 years, in 6 half-year editions, allowed the author to record 16462 observations with regard to the measurement of 48 parameters describing feet, body weight and height. The photogrammetric method was used to measure the selected parameters.

Conclusions

1. Among children aged 7-13 years, body height revealed significantly more frequent correlations with the parameters of feet than body weight.

Body height was reported to reveal more frequent significant correlations with the parameters of feet than body weight among boys and girls. As regards girls involved in the study, the proportions concerning the frequency of relationships concerning body height were similar to the percentage represented by boys whereas body-weight-related correlations were more
\end{abstract}


frequent. Body weight and height were reported to correlate more often with the parameters of feet in the case of children living in the urban areas than those from the rural regions.

2. Among boys, the most frequent significant correlations between body weight and height and the parameters of feet were observed in subjects living in the urban environment. The percentage of relationships between body weight parameters observed in the rural environment was very low. Among girls from towns and cities, the prevalence of correlations between body weight and height outnumbered the rate of relationships in the rural environment.

Key words: body weight and height, parameters of feet

\section{Introduction}

According to a systematic literature review of the issue mentioned herein, it is clear that authors often focus on correlations between body weight and feet architecture in various aspects $[1,2,3]$. Feet are a significant static and dynamic link in the musculoskeletal system as they keep body mass within the real limits of balance thus providing this mass with a drive at the same time [4]. The issue of interdependence between somatic characteristics and parameters of feet usually relates to correlations concerning the longitudinal foot arch $[5,6]$. A large percentage of disorders connected with body posture statics is often associated with a sedentary lifestyle as well as with body weight and height. A student's environment considerably affects the type and magnitude of mistakes, particularly during the period of school shock $[7,8]$. The research conducted by Drzał-Grabiec et al. concerning body posture, weight and height, in the group of 563 pupils of the first three grades of primary school revealed statistically significant differences between the parameters regarding body posture, weight and height [9]. The study carried out by Pauk et al. among 450 primary school pupils concerning the verification of the impact of selected epidemiologic factors on flat feet in children which was expected to lead to development of a mathematical model describing the correlations between the height of the longitudinal arch and such factors as age, gender, Cole's weight and height index and the place of residence, revealed that the height of the longitudinal arch was most influenced by age and Cole's index. In addition, the study found that the longitudinal arch height increased with age whereas Cole's index decreased when the foot arch became smaller [10]. 
The study conducted by Puszczałowska-Lizis et al. in the group of 50 pupils of the second grade reported that girls in the early-school years had better foot arches than boys, but in terms of the heel angle, the groups involved in the study were similar. It was also demonstrated that body mass parameters significantly affected the shape of the longitudinal arch both in girls and boys whereas the occurrence of correlations between Clarke's angle and body height in boys and lack of similar correlations in girls was probably the consequence of sexual dimorphism. Besides, it was observed that body weight and height did not have an impact on the transverse foot arch in children in the early-school years [11]. The research performed by Mikołajczyk and Jankowicz-Szymańska in the group of 90 children aged 7 found that static flat feet was a common defect observed in 7-year-olds, especially in boys, while adipose tissue degree and position of lower limbs had no significant impact on the degree of foot arch. It was also observed that excessive adipose tissue expressed by increased body mass and abdominal skinfold thickness increased the risk of valgus knees in children of both sexes [3].

The purpose of this study was to present the incidence of significant correlations between body weight and height and the selected parameters of feet among 7-13-year-old children. The analysis of the research conclusions headed in four directions. The first one was to provide an answer to the question: which parameters of feet most frequently revealed a significant relationship with body weight and height at the age of 7-14 years? The second and third directions were to give an answer to the question: with which parameters was there a significant correlation revealed within sexual and environmental dimorphism? The fourth one was an answer to the question: what was the frequency of significant correlations of body weight and height among boys and girls within each of the above-mentioned environments?

\section{Material and methods}

The study conducted among children aged 7-13 years during the period of 3 years, in 6 halfyear editions, allowed the researcher to record 16,462 observations including 8,953 girls and 7,509 boys. with regard to the measurement of 48 parameters describing feet, body weight and height. The statistical analysis covered body weight and height and 48 angular and linear parameters of feet in particular age, sex and environmental categories, Table 1. 
Table 1. The List of recorded parameters of feet, body weight and height

\begin{tabular}{|c|c|c|c|c|}
\hline \multicolumn{3}{|c|}{ Symbol } & \multicolumn{2}{|r|}{ Parameters } \\
\hline No. & & Unit & Name & Description \\
\hline 1 & DL p & \multirow[t]{6}{*}{$\mathrm{mm}$} & Length of the right & \multirow{2}{*}{$\begin{array}{l}\text { Distance between points acropodion } \\
\text { and pterion in a plantogram }\end{array}$} \\
\hline 2 & DL 1 & & foot (p), left foot (1) & \\
\hline 3 & Szp & & \multirow{2}{*}{$\begin{array}{l}\text { Width of the right } \\
\text { foot (p), left foot (1) }\end{array}$} & \multirow{2}{*}{$\begin{array}{l}\text { Distance between points metatarsal } \\
\text { fibular and metatarsal tibial in a } \\
\text { plantogram }\end{array}$} \\
\hline 4 & $\mathrm{Sz} 1$ & & & \\
\hline 5 & $\mathrm{~W} p$ & & \multirow{2}{*}{$\begin{array}{l}\text { "W" Indicator } \\
\text { (Wejsflog indicator) } \\
\text { of the right foot }(\mathrm{p}) \text {, } \\
\text { of the left foot }(1)\end{array}$} & \multirow[t]{2}{*}{$\begin{array}{l}\text { The relationship of foot length to its } \\
\text { width } \\
\text { DL } p / S z p=W p, D L 1 / S z l=W 1\end{array}$} \\
\hline 6 & W 1 & & & \\
\hline 7 & $\begin{array}{ll}\text { Alfa } & p \\
m\end{array}$ & \multirow[t]{9}{*}{ degree } & \multirow{4}{*}{$\begin{array}{l}\text { Valgity angle of big } \\
\text { toe of the right } \\
\text { foot: Alfa } p \text {, of } \\
\text { the left foot: Alfa } 1 \\
\text { p. Angle of varus } \\
\text { deformity in the } \\
\text { right foot: } \\
\text { Alfa } p \text { m, left foot: } \\
\text { Alfa } 1 \mathrm{~m} \text {. }\end{array}$} & \multirow{4}{*}{$\begin{array}{l}\text { Angle between the straight line passing } \\
\text { through points metatarsal tibial and the } \\
\text { most inner one on the medial edge of } \\
\text { the heel and the straight line passing } \\
\text { through points metatarsal tibial and the } \\
\text { most inner one on the medial edge of } \\
\text { the great toe }\end{array}$} \\
\hline 8 & Alfa $p p$ & & & \\
\hline 9 & Alfa $1 \mathrm{~m}$ & & & \\
\hline 10 & Alfa $1 \mathrm{p}$ & & & \\
\hline 11 & $\begin{array}{ll}\text { Beta } & p \\
m\end{array}$ & & \multirow{4}{*}{$\begin{array}{l}\text { Angle of varus } \\
\text { deformity of the } 5^{\text {th }} \\
\text { toe of the right } \\
\text { foot: Beta } p \text {, of } \\
\text { the left foot: Beta } 1 \\
\text { p. } \\
\text { Valgity angle of the } \\
\text { fifth toe of the right } \\
\text { foot: Beta } p \mathrm{~m} \text {, left } \\
\text { foot: Beta } 1 \mathrm{~m} \text {. }\end{array}$} & \multirow{4}{*}{$\begin{array}{l}\text { Angle between the straight line passing } \\
\text { through points metatarsal fibular and } \\
\text { the most outer } \\
\text { one on the lateral edge of the heel and } \\
\text { the straight line passing through points } \\
\text { metatarsal fibular and the most outer } \\
\text { one on the lateral edge of the fifth toe } \\
\text { in a plantogram }\end{array}$} \\
\hline 12 & \begin{tabular}{|l|} 
Beta $p$ \\
$p$
\end{tabular} & & & \\
\hline 13 & $\begin{array}{ll}\text { Beta } 1 \\
\mathrm{~m}\end{array}$ & & & \\
\hline 14 & Beta $1 \mathrm{p}$ & & & \\
\hline 15 & $\begin{array}{l}\text { Gamma } \\
\mathrm{P}_{(\text {Gam.P) }}\end{array}$ & & \multirow[t]{2}{*}{$\begin{array}{l}\text { Heel angle of right } \\
\text { foot (p), of left foot } \\
\text { (1) }\end{array}$} & \multirow[t]{2}{*}{$\begin{array}{l}\text { Angle between the straight line passing } \\
\text { through points metatarsal tibial and the } \\
\text { most inner one on the medial edge of } \\
\text { the heel and the straight line passing } \\
\text { through points metatarsal fibular and } \\
\text { the most outer one on the lateral edge } \\
\text { of the heel in a plantogram }\end{array}$} \\
\hline 16 & \begin{tabular}{|l|} 
Gamma \\
1 (Gam. L)
\end{tabular} & & & \\
\hline 17 & PS p & \multirow[t]{2}{*}{$\mathrm{mm}^{2}$} & \multirow{2}{*}{$\begin{array}{l}\text { Plantar surface of } \\
\text { right foot }(p) \text {, left } \\
\text { foot }(1)\end{array}$} & \multirow[t]{2}{*}{ Plantar surface of the foot } \\
\hline 18 & PS 1 & & & \\
\hline 19 & DP 1 & \multirow[t]{5}{*}{$\mathrm{mm}$} & \multirow{5}{*}{$\begin{array}{l}\text { Length of } \\
\text { longitudinal arch } 1 \text {, } \\
2,3,4 \text {, and } 5 \text { of } \\
\text { right foot }(\mathrm{P}) \text {, left } \\
\text { foot (L) }\end{array}$} & \multirow{5}{*}{$\begin{array}{l}\text { Length of the arch from } 1,2,3,4 \text { and } 5 \\
\text { metatarsal foot to point pterion }\end{array}$} \\
\hline 20 & DP 2 & & & \\
\hline 21 & DP 3 & & & \\
\hline 22 & DP 4 & & & \\
\hline 23 & DP 5 & & & \\
\hline
\end{tabular}




\begin{tabular}{|c|c|c|c|}
\hline 24 & DL 1 & & \\
\hline 25 & DL 2 & & \\
\hline 26 & DL 3 & & \\
\hline 27 & DL 4 & & \\
\hline 28 & DL 5 & & \\
\hline 29 & WP 1 & \multirow{10}{*}{$\begin{array}{l}\text { Height of arch } 1,2 \text {, } \\
3,4 \text { and } 5 \text { of right } \\
\text { foot (P), left foot } \\
\text { (L) }\end{array}$} & \multirow{10}{*}{$\begin{array}{l}\text { Distance from the bottom to the highest } \\
\text { point of arch 1, 2, 3, } 4 \text { and } 5 \text {. }\end{array}$} \\
\hline 30 & WP 2 & & \\
\hline 31 & WP 3 & & \\
\hline 32 & WP 4 & & \\
\hline 33 & WP 5 & & \\
\hline 34 & WL 1 & & \\
\hline 35 & WL 2 & & \\
\hline 36 & WL 3 & & \\
\hline 37 & WL 4 & & \\
\hline 38 & WL 5 & & \\
\hline 39 & SP 1 & \multirow{10}{*}{$\begin{array}{l}\text { Width of arch } 1,2 \text {, } \\
3,4 \text { and } 5 \text { of right } \\
\text { foot (P), left foot } \\
\text { (L) }\end{array}$} & \multirow{10}{*}{$\begin{array}{l}\text { Bowstring of the distance of arch } 1,2 \text {, } \\
3,4 \text { and } 5 \text {. }\end{array}$} \\
\hline 40 & SP 2 & & \\
\hline 41 & SP 3 & & \\
\hline 42 & SP 4 & & \\
\hline 43 & SP 5 & & \\
\hline 44 & SL 1 & & \\
\hline 45 & SL 2 & & \\
\hline 46 & SL 3 & & \\
\hline 47 & SL 4 & & \\
\hline 48 & SL 5 & & \\
\hline
\end{tabular}

\begin{tabular}{|l|l|l|l|l|}
\hline 49 & $\mathrm{Mc}$ & $\mathrm{kg}$ & Body mass & $\begin{array}{l}\text { Measurements were conducted on the medical } \\
\text { scales with accuracy to } 0.5 \mathrm{~cm} \text { and } 100 \mathrm{~g} .\end{array}$ \\
\hline 50 & $\mathrm{Wc}$ & $\mathrm{cm}$ & Body height & Bcale \\
\hline
\end{tabular}

Source: author's own research

The key assumption of the study was to always assess the habitual posture as a relatively constant individual characteristic of a human being. This posture reflects an individual emotional, psychical and social condition of the subject. Moreover, this posture provides the most reliable description of the subject's silhouette at a given time and in a place. The conducted diagnostics did not determine whether an individual's posture was correct or not, it only identified the condition of its ontogenetic development. Objectified and comparable test results ensured that the postural parameters adopted for the analysis were recorded with possible to determine compensations. The combined assessment of the trunk and feet allowed to objectively determine the quality of the postural model applied in a given environment, gender and age category. The measuring instrument used in the study determined several tens of parameters describing the feet. Obtaining the spatial picture was possible thanks to displaying the lines of strictly defined parameters on a subject's feet. The lines falling on the skin got distorted depending on the surface configuration. The applied lens ensured that the 
imaging of the feet could be received by a special optical system with a camera, then transmitted to the computer monitor. The distortions of the line imaging recorded in the computer memory were processed through a numerical algorithm on the topographic map of the investigated surface. When conducting the study, one should be aware of the fact that the taken photo records an image of the silhouette displayed on an individual's skin [12].

The empirical data was the quantitative and qualitative characteristics (gender, place of residence, etc.). The conducted calculations covering the values of position statistics (arithmetic mean, quartiles), the dispersion parameter (standard deviation) and symmetry indicators (asymmetry and concentration indicators) provided a comprehensive view of the distribution of the studied features considering age ranges, gender and environment. The relationships and their significance were assessed using p-value and frequency expressed in percentage.

\section{Findings}

Due to the article constraints, the detailed description of the somatic features of the study material and the results obtained are available in the author's monography [12]. Body weight revealed a significant correlation with the following parameters: length, width and sole surface of feet, the size of transverse foot arch (Gamma angle) and the angle of valgus inclination of the fifth toe in the left foot, length of five longitudinal arches in the right foot and the first and fourth toe of the left one, width of five longitudinal arches in the right and left foot, height of the first, third, fourth and fifth longitudinal arch in the right foot and the first, second, third and fourth toe of the left foot. Body height was reported to significantly correlate with the following parameters: length and width of feet, sole surface, valgus inclination of the fifth toe and length and width of five longitudinal arches, height of five longitudinal foot arches, the size of the transverse foot arch and valgus inclination of the big toe in the right foot.

The statistical analysis suggested that the frequency of significant correlations between body height and foot parameters in 7-13-year-old children was $83.33 \%$ and in the case of body weight it was $70.83 \%$. Interference concerning the frequency of significant correlations only within gender showed that among boys

Interference concerning the frequency of significant correlations only within gender showed that among boys the frequency regarding body height correlations was $79.16 \%$ and with body weight it was $45.83 \%$. As far as girls were concerned, the figures were respectively $81.25 \%$ and $62.5 \%$. The profile of the environmental analysis revealed that the frequency of significant correlations between body height and foot parameters was $83.33 \%$ and body 
weight $60.41 \%$ in the individuals living in urban areas. In the case of children living in rural areas, the figures were respectively: $81.25 \%$ and $45.83 \%$, Table 2, Fig. 1.

Table 2. The percentage of significant correlations between body weight and height and the parameters of feet with regard to age, gender and environment (n) $K=8953$, $M=7509$

\begin{tabular}{|l|l|l|}
\hline $\begin{array}{l}\text { Profile of the } \\
\text { analysis }\end{array}$ & $\begin{array}{l}\text { Body height } \\
\text { and weight }\end{array}$ & $\begin{array}{l}\text { Correlation } \\
\text { percentage }\end{array}$ \\
\hline $\begin{array}{l}\text { Age range } \\
\text { from 4 to } 6 \\
\text { years }\end{array}$ & $\mathrm{Wc}$ & 83.33 \\
\cline { 2 - 3 } & $\mathrm{Mc}$ & 70.83 \\
\hline Gender & $\mathrm{M} \mathrm{Wc}$ & 79.16 \\
\cline { 2 - 3 } & $\mathrm{M} \mathrm{Mc}$ & 45.83 \\
\cline { 2 - 3 } & $\mathrm{K} \mathrm{Wc}$ & 81.25 \\
\cline { 2 - 3 } & $\mathrm{K} \mathrm{Mc}$ & 62.5 \\
\hline Environment & $\mathrm{M} \mathrm{Wc}$ & 83.33 \\
\cline { 2 - 3 } & $\mathrm{M} \mathrm{Mc}$ & 60.41 \\
\cline { 2 - 3 } & $\mathrm{W} \mathrm{Wc}$ & 81.25 \\
\cline { 2 - 3 } & $\mathrm{W} \mathrm{Mc}$ & 45.83 \\
\hline
\end{tabular}

Source: author's own study

Fig. 1. Percentage of significant correlations between body weight and height with parameters of feet depending on the range of age, gender and environment (n) $W=8953, M=7509$

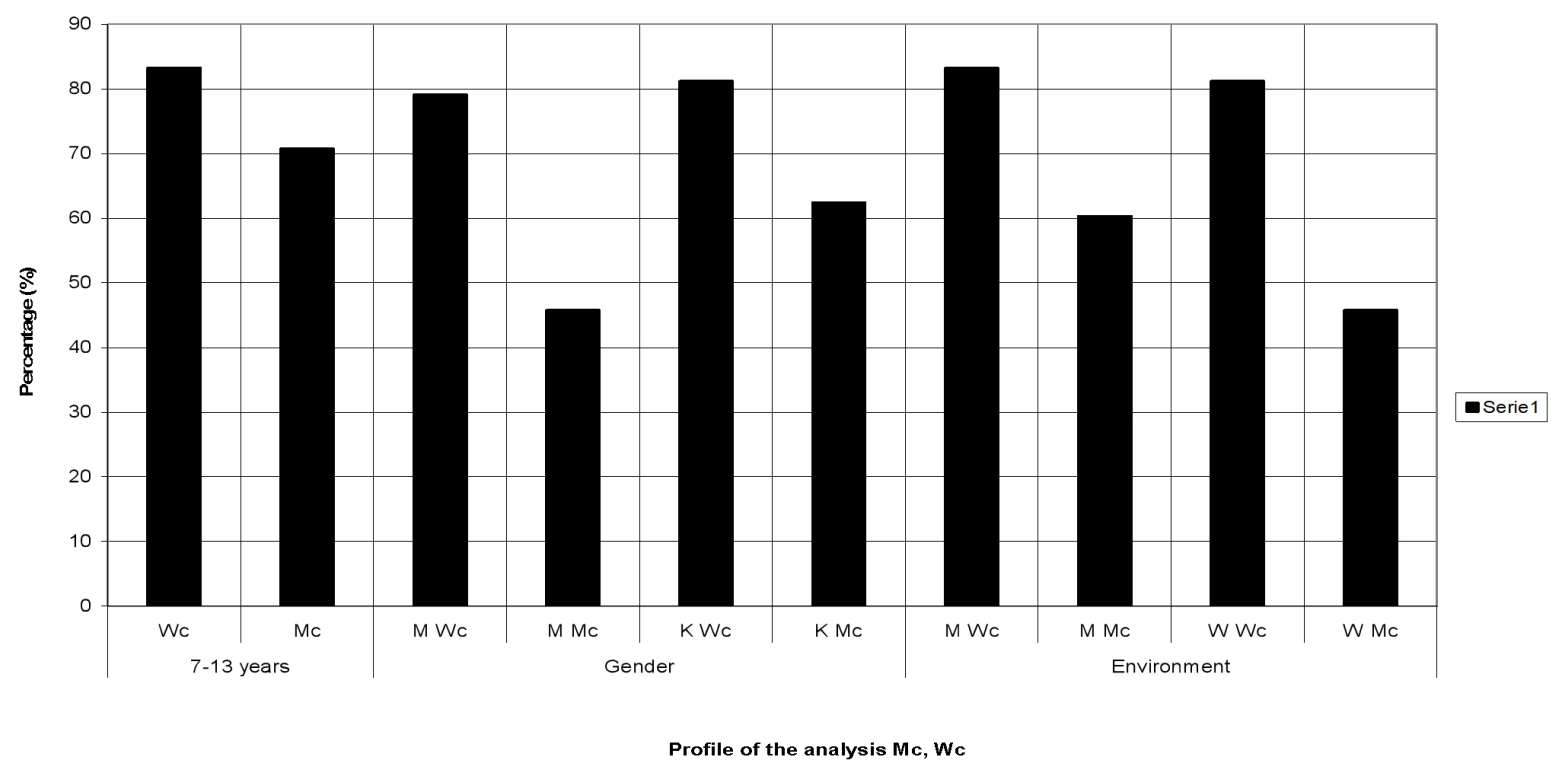

Legend, Table 2, Fig. 1: Wc - body height, Mc - body weight, line "Sex": M - male sex, K female sex, line "Environment": M - urban, W - rural. 
More detailed defining of the percentage of significant environmental correlations suggested that among boys from towns and cities, body height correlated with foot parameters at the level of $75.0 \%$, and body weight only at $41.66 \%$, whereas among the subjects from villages the numbers were respectively: $70.83 \%$ and $6.25 \%$. The frequency of significant correlations concerning body height among girls from urban areas was $81.25 \%$, body weight $60.41 \%$, and among girls from rural areas $77.08 \%$ and $41.66 \%$, Table 3, Fig. 2.

Table 3. The percentage of significant correlations between body weight and height and the parameters of feet in female and male subjects from both environments (n) $K=8953$, $\mathrm{M}=7509$

\begin{tabular}{|l|l|l|}
\hline $\begin{array}{l}\text { Profile of the } \\
\text { analysis }\end{array}$ & $\begin{array}{l}\text { Body height } \\
\text { and weight }\end{array}$ & $\begin{array}{l}\text { Correlation } \\
\text { percentage }\end{array}$ \\
\hline \multirow{2}{*}{ M M } & Wc & 75.0 \\
\cline { 2 - 3 } & Mc & 41.66 \\
\hline \multirow{2}{*}{ M W } & Wc & 70.83 \\
\cline { 2 - 3 } & Mc & 6.25 \\
\hline \multirow{2}{*}{ K M } & Wc & 81.25 \\
\cline { 2 - 3 } & Mc & 60.41 \\
\hline \multirow{2}{*}{ K W } & Wc & 77.08 \\
\cline { 2 - 3 } & Mc & 41.66 \\
\hline
\end{tabular}

Source: author's own study

Fig. 2. Percentage of significant correlations between body weight and height of feminine and masculine subjects depending on the environment (n) $W=8953, M=7509$

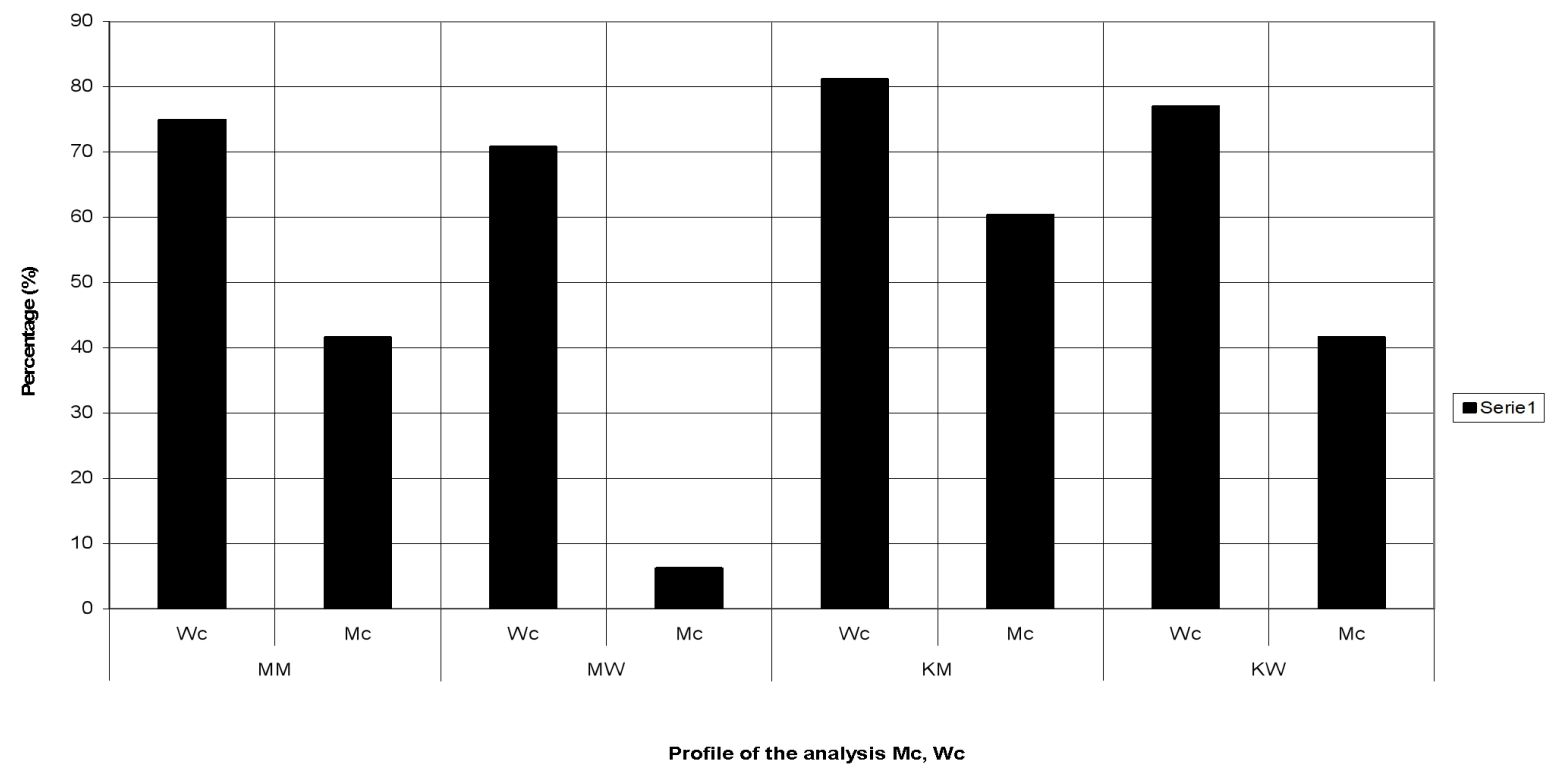

Legend, Table 3, Fig. 2: MM - male sex, urban, MW - male sex, rural, KM - female sex, urban, KW - female sex, rural. 


\section{Discourse}

The development of information technology has resulted in development of normative ranges for the parameters describing body posture, which would enable further research of their mutual influence, correlations and coexistence. To a large extent, however, authors merely determined correlations or coexistence of somatic parameter and postural features. The available literature of the subject has not mentioned any research results determining the frequency of significant correlations between somatic parameters and selected body trunk features. Scientists have tended to focus on establishing relationships or coexistence regarding body height and weight with foot parameters rather than human trunk parameters.

A pilot study, conducted by Drzat-Grabiec and Snela on the population of 563 girls and boys at the age from 7 to 9 years, allowed the researchers to determine relationships between longitudinal arch of the right and left feet calculated using Clarke's angle and length parameters describing body posture. According to studies performed, there is a statistically significant correlation between longitudinal arch of both feet calculated using Clarke's angle and spine height calculated between points $C_{7}$ and $S_{1}$. This correlation is confirmed when taking the subgroups of boys and girls and age subgroups into consideration. Age ranges showed only a statistically significant correlation in the group of 9-year-olds [13]. The studies conducted by Bogucka et al. found that the body weight deficiency and overweight provided conducive biochemical conditions for disorders of statics of the musculoskeletal system, the positioning of lower extremities and foot arches [14]. Similar conclusions were drawn by other authors as well $[15,16]$. Górniak et al. came to a conclusion that sagittal curvatures of incorrect angular and linear parameters occurred regardless of fat deposition in $50 \%$ of diagnosed children. Interestingly enough, incorrect body postures were observed most often in respondents with excessive fat deposition [17]. The research concerning body posture and mass conducted by Ostrowska et al. in a group of 70 children suggested that excessive body weight and fat deposition increase led to gradual flattening of thoracic kyphosis or even to linear dependence in case of lumbar lordosis [18]. The studies performed by MaciałczykPaprocka et al. in a group of 1,176 pupils aged 7-12 years demonstrated that overweight and obesity predisposed to the occurrence of postural defects, especially among girls [19]. Wilczyński came to a conclusion based on the results of measurements conducted on the population of 503 children at the age of 12-15 years that individuals with sagittal plane posture defects were shorter, lighter and with lower BMI, and the highest rate of sagittal plane posture defects was observed in a group with height, weight and BMI below the $25^{\text {th }}$ quartile. 
The author also proved that sagittal plane posture defects most often appeared among children with fragile body build. He did not observe any correlations between incidence of sagittal plane posture defects and height, weight and BMI expressed in quartiles [20].

\section{Conclusions}

1. Among children aged 7-13 years, body height revealed significantly more frequent correlations with the parameters of feet than body weight.

2. Body height was reported to reveal more frequent significant correlations with the parameters of feet than body weight among boys and girls. As regards girls involved in the study, the proportions concerning the frequency of relationships concerning body height were similar to the percentage represented by boys whereas body-weight-related correlations were more frequent. Body weight and height were reported to correlate more often with the parameters of feet in the case of children living in the urban areas than those from the rural regions.

3. Among boys, the most frequent significant correlations between body weight and height and the parameters of feet were observed in subjects living in the urban environment. The percentage of relationships between body weight parameters observed in the rural environment was very low. Among girls from towns and cities, the prevalence of correlations between body weight and height outnumbered the rate of relationships in the rural environment.

4. The correlations presented herein are important in terms of posturogenesis occurring in the selected age range. They should draw the attention of parents and teachers to an undeniably large impact of body height and weight on postural parameters within trunk and not only and feet.

\section{References}

1. E. Puszczałowska-Lizis, Correlations between transverse arches of feet and selected morphological features in young adults, Physiotherapy, 2011, 19, 1, 3-9.

2. E. Barańska, E. Gajewska, M. Sobieska, Obesity and consequential musculoskeletal system problems and motor skills of girls and boys with overweight and simple obesity. Medical News, 2012, 81, 4, 337-341.

3. E. Mikołajczyk, A. Jankowicz-Szymańska, Effects of fat deposition on foot arch and formation of lower extremities in 7-year-old children, Physiotherapy 2010, 18, 2, 10-20.

4. J. W. Błaszczyk, Clinical biomechanics, Medical Publishing PZWL, Warsaw, 2004. 
5. Yang S. M., Kayamo J., Noriamatsu T., Fujita M., Matsusaka N., Suzuki R., Okamura H. Dynamic changes of the arch of the foot during walking. Biomechanics IX-A. J. Hum. Kinet., $1985,417-422$.

6. Lizis P., Kasperczyk T., Szmigiel Cz., Całka-Lizis T., Emmerich W., Szczygieł P. Body posture and its relationships with morphological features in obese children, [at:] J. Ślężyński (Ed.) Body posture and its assessment methods. AWF, Katowice 1992, 99-107.

7. Mrozkowiak M. An attempt to determine the importance of GOOD CHAIR in the prevention of postural disorders. Journal of Health Sciences. 2014;4(4):195-214.

8. M. Mrozkowiak, H. Żukowska, The significance of Good Chair as part of children's school and home environment in the preventive treatment of body statistics distortions. Journal of Education, Health and Sport. 2015;5(7):179-215.

9. J. Drzał-Grabiec, S. Snela, B. Szczepanowska-Wołowiec, K. Bibrowicz, The study of correlations between selected postural parameters and body weight and height and the place of residence. Medical Review of the University of Rzeszów and the National Institute of Medicines in Warsaw, Rzeszów 2012, 4, 410-417.

10. J. Pauk, V. Ezerskiy, M. Rogalski, The impact of epidemiologic factors on flat feet in children, Physiotherapy, 2010, 18, 2.

11. E. Puszczałowska-Lizis, T. Ridan, M. Ogarek, Characteristics of the parameters of longitudinal and transverse foot arches in girls and boys in the early school years, Mołoda Sportiwna Nauka, Ukraine, 2011, Vol. 3, 234-239.

12. M. Mrozkowiak, Modulation, impact and correlations of selected body posture parameters in children and adolescents aged 4-18 years in the light of mora projection, Publishing House of Kazimierz Wielki University, Bydgoszcz, Volume I, II.

13. Drzał-Grabiec J., Snela S., 2012, Spinal curvatures and foot defects in children: an experimental study, Spine, 36-47.

14. Bogucka A., Głębocka A., Body posture of 9-12-year-old children with diversified body mass expressed with BMI, Physical activity and health, 2017, 12:11-17.

15. Barszczyk K., Skolimowski T., Anwajer J., Chamela-Blińska D., Somatic features and parameters of anterior-posterior spinal curvature in 7-years-old with particular posture types. Ortop.Traumatol. Rehabil, 2005, 7(5):555-562.

16. Pausić J., Cavala M., Katić R., Relations of the morphological characteristic latent structure and body posture indicators in children ages seven to nine years. Coll. Antropo. 2006. 30(3):621-627. 
17. Górniak K., Lichota M., Popławska H., Dmitruk A., Body posture of boys from rural areas, with insufficient or excessive adipose tissue, Rocznik Lubuski 2014, 40 (2):163-176.

18. Ostrowska B., Barczyk K., Hawrylak A., Body posture of overweight, obese children, Nowiny Lekarskie, 2002, 2-3:160-163.

19. Maciałczyk-Paprocka K., Krzyżaniak A., Kotwicki T., Sowińska A., StawińskaWitoszyńska B., Krzywińska-Wiewiorowska, Przybylski J., Occurrence of posture mistakes in primary school pupils from Poznań, Prob. Hig. Epidemi., 2012, 93(2), 309-314.

20. Wilczyński J., Body posture and somatic features in children aged 12-15 years from Świętokrzyskie voivodeship, Medical studies, 2011, 24(4), 29-33. 